\title{
PEMBERDAYAAN MASYARAKAT WILAYAH 3T (TERDEPAN,TERLUAR, TERTINGGAL) DI KECAMATAN SEBATIK BARAT KABUPATEN NUNUKAN MELALUI REVOLUSI MENTAL DALAM MEWUJUDKAN INDONESIA BERSIH DAN INDONESIA BERSATU
}

\author{
Community Empowerment Area 3T (Leading Edge, Outer, Left) In Nunukan Regency West \\ Sebatik Through A Mental Revolution In Realizing Clean And United Indonesia
}

\author{
Daud Nawir ${ }^{1}$, Achmad Zultan ${ }^{2}$ \\ Fakultas Teknik, Universitas Borneo Tarakan \\ Jl. Amal Lama No.1, Tarakan KAL-TARA \\ Email: daudnawir@gmail.com
}

\begin{abstract}
ABSTRAK
Tujuan PKM adalah melatih masyarakat dan memberikan pembekalan ilmu pengetahuan untuk mengembangkan potensi alam maupun potensi yang ada di dalam diri masyarakat. Melalui gerakan Indonesia Bersih PKM Revolusi Mental Universitas Borneo Tarakan menuju kesadaran dan kepedulian baik masyarakat maupun pemerintahan desa terhadap kebersihan lingkungan yang diimplementasikan pada contoh pemanfaatan limbah atau sampah rumah tangga; meningkatkan kesadaran nasionalisme, kehidupan harmonis di masyarakat desa tanpa ada diskriminasi terhadap kaum minoritas dan meningkatkan perilaku yang mendukung kehidupan demokrasi masyarakat desa. Kegiatan pengabdian ini dilakukan di kecamatan Sebatik Barat dengan fokus Desa Bambangan, Desa Liang Bunyu dan Desa Setabu. Pengabdian masyarakat berbasis revolusi mental merupakan gerakan nasional untuk mengubah pandang, pola pikir, sikap-sikap, nilai-nilai, dan perilaku masyarakat kecamatan sebatik barat untuk mewujudkan masyarakat berdaulat dan berkepribadian yang bertumbu pada tiga nilai-nilai dasar yaitu Integritas, Etos Kerja, dan Gotong Royong. Metode yang digunakan adalah metode partisipatoris. Hasil kegiatan pengabdian berjalan dengan baik. Kegiatan tersebut meliputi: pengadaan tempat sampah di sekitar lingkungan desa, pembuatan Vertikultur dengan memanfaatkan lahan sempit, Sosialisasi Bahaya limbah plastik, dan kerja bakti bersih-bersih pantai. Berdasarkan data wawancara masih banyak masyarakat dan perangkat desa yang puas dan memahami gerakan revolusi mental Indonesia bersih sebanyak 78\%. Minimnya sosialisasi gerakan revolusi mental secara massif merupakan salah satu alasan diperlukan kegiatan sosialisasi gerakan revolusi mental secara massif dan berkesinambungan agar masyarakat memahami dan berdampak akan perubahan tingkah laku di masyarakat kecamatan Sebatik Barat.
\end{abstract}

Kata Kunci: pemberdayaan masyarakat, daerah 3T, revolusi mental, Indonesia bersih, Indonesia bersatu

\begin{abstract}
The purpose of PKM is to practice the community and provide of knowledge to develop the potential of nature and potential exist within the community. Through the movement of Indonesia clean of Mental Revolution based on University of Borneo Tarakan to awareness and care both community and village government on the cleanliness of the environment that is implemented in the example of utilization of waste or household waste; raising awareness of nationalism, harmonious life in rural communities without any discrimination against minorities and promoting behaviors that support the democratic life of rural communities. This community engagement were conducted in West Sebatik sub-district with the focus of Brambangan, Liang Bunyu and Setabu Village. Community-based mental revolutionary community is a national movement to change the views, mindsets, attitudes, values, and behavior of western subdistrict communities to realize sovereign and personable societies that cultivate on three basic values of Integrity, Work Ethics, and Mutual cooperation. The method used is a participatory method. The results of the devotion work well. These activities were included: procurement of waste bins around the village environment, making Vertikultur by utilizing narrow land, Socialization Hazards of plastic waste, and clean-up work of the beach. Based on interview data there are still many people and village apparatus who are satisfied and understand mental revolution movement of Indonesia as much as 78\%. The lack of socialization of the massive revolutionary movement is one of the
\end{abstract}

Daud N., Achmad Z., Pemberdayaan Masyarakat Wilayah... 
reasons for the massive and sustained socialization of massive and massive mental revolutionary movements in order for the public to understand and impact on behavioral changes in the West Sebatik district community.

Key words: community empowerment, 3T areas, mental revolution, clean of Indonesia, united of Indonesia

\section{PENDAHULUAN}

Kalimantan Utara merupakan provinsi muda di Indonesia yang saat ini sedang berusaha mengejar ketertinggalan pembangunan dan kesejahteraan masyarakatnya. Provinsi Kalimantan Utara terletak di paling utara Pulau Kalimantan, merupakan wilayah perbatasan dengan Negara Malaysia. Provinsi Kalimantan Utara memiliki kekayaan Sumber daya alam yang melimpah dan mempunyai potensi terus berkembang. Areal perkebunan di Kalimantan Utara secara keseluruhan pada tahun 2013 adalah 189.449 ha, Luas hutan Kalimantan Utara tahun 2013 sekitar 4.830.032,31. Jumlah Penduduk Kalimantan Utara sebesar 618.208 jiwa pada tahun 2014, jumlah sumber daya manusia yang belum memadai untuk melakukan pengelolaan dan pengembangan potensi daerah. Salah daerah yang belum memadai dalam pemberdayaan sumberdaya manusia yaitu Kabupaten Nunukan.

Kabupaten Nunukan merupakan wilayah yang 13 kecamatannya terletak pada garis perbatasan antara Republik Indonesia dengan Malaysia (Sabah dan Serawak). Dengan posisi yang strategis tersebut menjadikan wilayah Kabupaten Nunukan sebagai cermin dan halaman depan dari berbagai aktivitas perekonomian lintas batas atau antar negara, sehingga dengan demikian perlu mendapat perhatian khusus, terutama terhadap penanganan berbagai permasalahan yang timbul yang terkait dengan eksistensi wilayah perbatasan. Salah satunya yaitu Kecamatan Sebatik Barat merupakan kecamatan dengan wilayah terluas, yaitu 93,27 $\mathrm{km} 2$ atau sekitar $0,65 \%$ dari luas Kabupaten Nunukan. Selain itu, kecamatan ini juga memiliki empat desa yaitu desa Bambangan, Desa Liang Bunyu, Desa Binalawan, dan Desa Setabu.

Kecamatan Sebatik Barat memiliki 4 desa, yang diantaranya memiliki tingkat kemiskinan berdasarkan data BPMPD Kabupaten Nunukan Tahun 2016 yaitu Desa Bambangan, Desa Liang Bunyu dan Desa Setabu. Mata pencarian utama sebagian besar desa di Sebatik Barat Nelayan dengan produksi perikanan tangkap, selain itu juga tanaman pangan diantaranya ubi kayu, padi, jagung dan ubi jalar. Selain tanaman pangan, komoditas hortikultura (buah dan sayuran) juga sedang di kembangkan oleh masyarakat desa di Sebatik Barat diantaranya cabe rawit, belimbing, duku, durian, mangga, nangka, nanas papaya, pisang, rambutan dan sirsak. Permasalahan yang dihadapi di desa wilayah perbatasan 3T (terdepan, terluar dan tertinggal) yaitu penataan ruang desa, permasalah $\mathrm{n}$ kebersihankesehatan karena kurangna fasilitas kesehatan dan pola hidup yang tidak sehat. Tetapi yang menjadi maslah yang serius lainnya yaitu terancamnya nasionalisme, dimana wilayah perbatasan 
(e-ISSN: 2579-9797)

Diterima: Mei 2018

Dipublikasikan: Juni 2018

perlunya pemupukan rasa persatuan. Hal

ini diakibatkan karena keseharian

masyarakat desa berinteraksi dengan perekonomian masyarakat Malaysia.

Program pengabdian masyarakat Universitas Borneo Tarakan ini diharapkan mahasiswa dapat menggali potensi sumber daya alam dan mengembangkan sumber daya manusia yang tersedia. Akademika UBT bersama masyarakat dan para mitrakerja untuk bersinergi dalam mengembangkan dan mengimplementasikan program REVOLUSI MENTAL untuk menyelesaikan suatu permasalahan dan mewujudkan pembangunan berkelanjutan. Dimana revolusi mental ajakan mengubah cara pandang, pikiran, sikap perilaku yang berorientasi pada kemajuan dan kemodernan, sehingga Indonesia menjadi bangsa besar dan mampu berkompetisi dengan bangsa-bangsa lain. Langkah selanjutnya berupa penetapan bidang strategis yang dapat dikembangkan di kecamatan Sebatik Barat dengan fokus Desa Bambangan, Desa Liang Bunyu dan Desa Setabu, sehingga dapat meningkatkan kebersihan, kesehatan, dan rasa nasionalisme daerah tersebut dalam bentuk pemberdayaan masyarakat. Untuk tujuan tersebut maka diusulkan program dengan tema: "Pemberdayaan Masyarakat Wilayah 3T (Terdepan, Terluar, Tertinggal) Melalui revolusi mental dalam mewujudkan indonesia bersih dan indonesia bersatu". Oleh karena itu diperlukan suatu pemahaman mengenai kendala-kendala yang dihadapi dan faktor ketidakberdayaan masyarakat sebagai perencanaan dan pemecahan masalah secara partisipatif. Kegiatan pengabdian di kecamatan Sebatik Barat dengan fokus
Desa Bambangan, Desa Liang Bunyu dan Desa Desa Setabu ini dibantu oleh berbagai pihak, seperti Bappeda Kalimantan Utara, BMPD kabupaten Nunukan dan Camat Sebatik Barat.

Tujuan PKM Universitas Borneo Tarakan Melatih masyarakat dan memberikan pembekalan ilmu pengetahuan untuk mengembangkan potensi yang dimiliki, baik potensi alam maupun potensi yang ada di dalam diri masyarakat. Melalui gerakan Indonesia Bersih PKM Revolusi Mental Universitas Borneo Tarakan Menuju kesadaran dan kepedulian baik masyarakat maupun pemerintahan desa terhadap kebersihan lingkungan yang diimplementasikan pada contoh pemanfaatan limbah atau sampah rumah tangga; dan Melalui gerakan Indonesia bersatu PKM Revolusi Mental Universitas Borneo Tarakan meningkatkan tingkat kesadaran nasionalismes, meningkatkan kehidupan harmonis di masyarakat desa tanpa ada diskriminasi terhadap kaum minoritas dan meningkatkan perilaku yang mendukung kehidupan demokrasi di masyarakat desa.

\section{METODE PENELITIAN}

\section{A. Tahap Persiapan}

1. PKM ini melibatkan mahasiswa sehingga melakukan wawancara untuk menjaring mahasiswa yang benar-benar komitmen terhadap program PKM yang ditawarkan, karena perlu keseriusan terlebih bhakti mahasiswa kepada masyarakat.

2. Adapun materi yang diberikan dalam sosialisasi PKM adalah tentang sosial budaya, pemberdayaan Pendidikan, Pemberdayaan Kesehatan Masyarakat, wawasan revolusi mental, bidang 
administrasi baik administrasi negara maupun hukum administrasi dan teknik.

3. Survei/Observasi ke lokasi, mitra dan kelompok masyarakat yang dijadikan sasaran PKM.yaitu di Kecamatan Sebatik Barat dengan fokus Desa Bambangan, Desa Liang Bunyu dan Desa Setabu.

4. Mengkomunikasikan program PKM dengan pemerintah daerah setempat, serta mitra lainnya

5. Membuat persetujuan dari kesepakatan kerjasama dengan Badan Pemberdayaan Masyarakat Desa (BPMD) Kabupaten Nunukan.

\section{B. Pelaksanaan Pengabdian}

\section{Kepada Masyarakat (PKM)}

Kegiatan ini dilaksanakan menggunakan metode partisipatoris. Jadi, pelaksanaan program dilakukan dengan melibatkan masyarakat setempat dan mahasiswa Kuliah Kerja Nyata sebagai fasilitator. Untuk itu, diperlukan pendampingan dalam setiap kegiatan agar dapat diketahui dinamika dari kegiata tersebut sehingga dapat mewujudkan tujuan pemberdayaan. Adapun kegiatan yang di rancang adalah: 1) Bimbingan teknis/Pendampingan/Penyuluhan berupa aktivitas kegiatan Pertanian mahasiswa bersama masyarakat; (2) Aktivitas pendukung lainnya dalam rangka mengembangkan Kesadaran kebersihan,

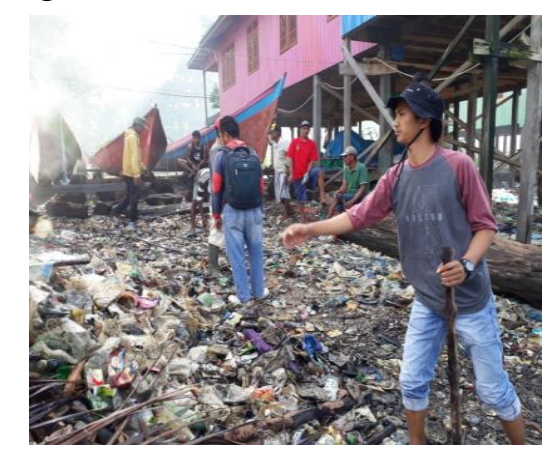

Gambar 1. Kegiatan Kerja bakti wilayah Pesisir yang diikuti oleh warga Desa Setabu

Daud N., Achmad Z., Pemberdayaan Masyarakat Wilayah... kesehatan dan lingkunga serta nasionalisme dengan program Gerakan Indonesia Bersih dan Gerakan Indonesia Bersatu.

\section{HASIL PENELITIAN}

\section{A. Aksi Revolusi Mental Gerakan Indonesia Bersih}

Gerakan Indonesia Bersih (GIB) adalah gerakan para penyelenggara negara dan masyarakat untuk mewujudkan perilaku hidup bersih dan sehat baik jasmani dan rohani pada semua simpul perubahan dan tingkatan kepemimpinan mengacu pada Pancasila dan UUD 1945. GIB memiliki fokus untuk menciptakan lingkungan yang bersih. Kebersihan lingkungan dapat berawal dari siapapun termasuk dari lingkungan rumah sendiri. Lingkungan akan lebih baik jika semua orang sadar dan bertanggungjawab akan kebersihan lingkungan, karena hal itu harus ditanamkan sejak dini, di sekolah pun kita diajarkan untuk selalu hidup bersih.

Seperti halnya kegiatan pengabdian masyarakat yang dilakukan pada desa Liang Bunyu, Desa Setabu dan Desa Bambangan dimana kegiatan meliputi pengadaan tempat sampah di sekitar lingkungan desa, pembuatan Vertikultur dengan memanfaatkan lahan sempit, Sosialisasi Bahaya limbah plastik, dan kerja bakti bersih-bersih pantai.

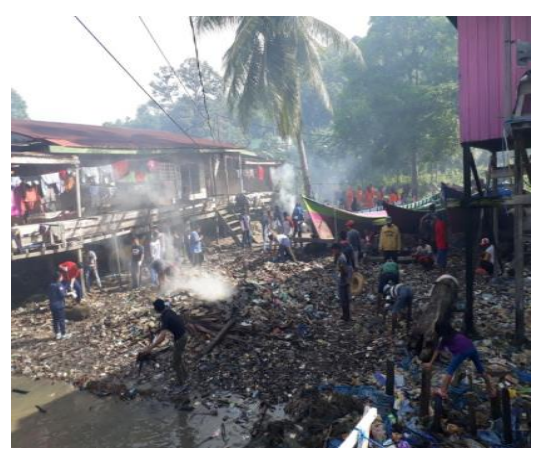



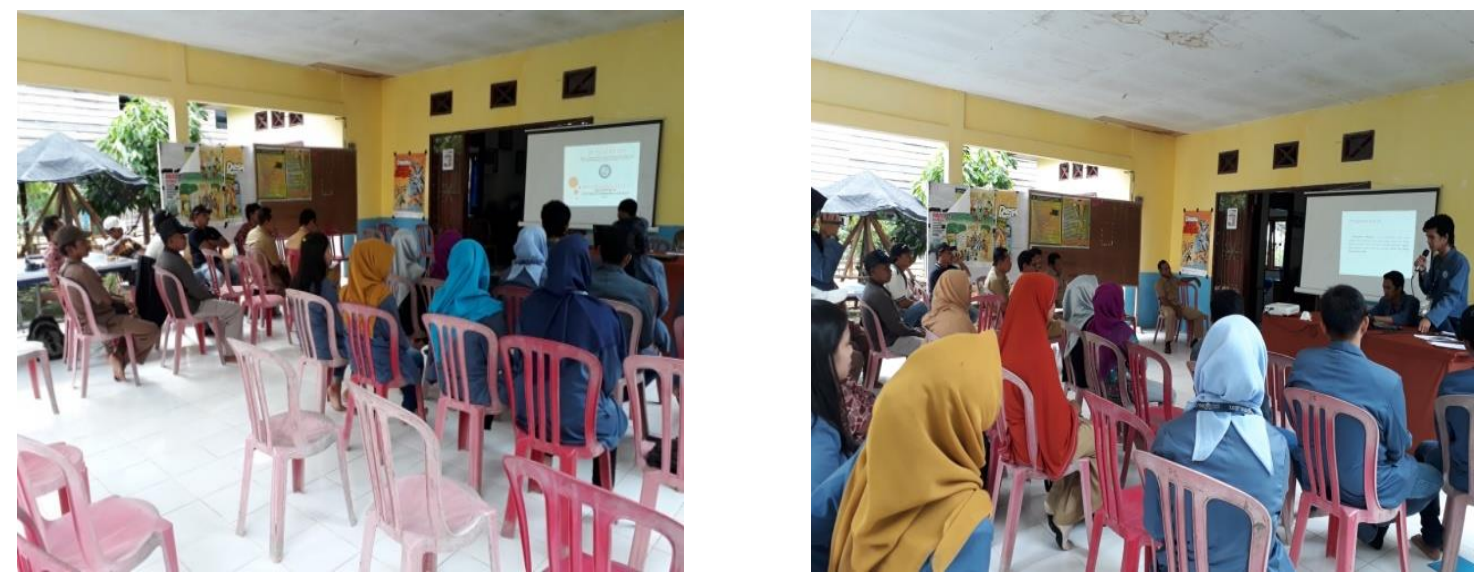

Gambar.2. Kegiatan Sosialisasi Tentang Bahaya Sampah Plastik Di Kantor Desa Setabu
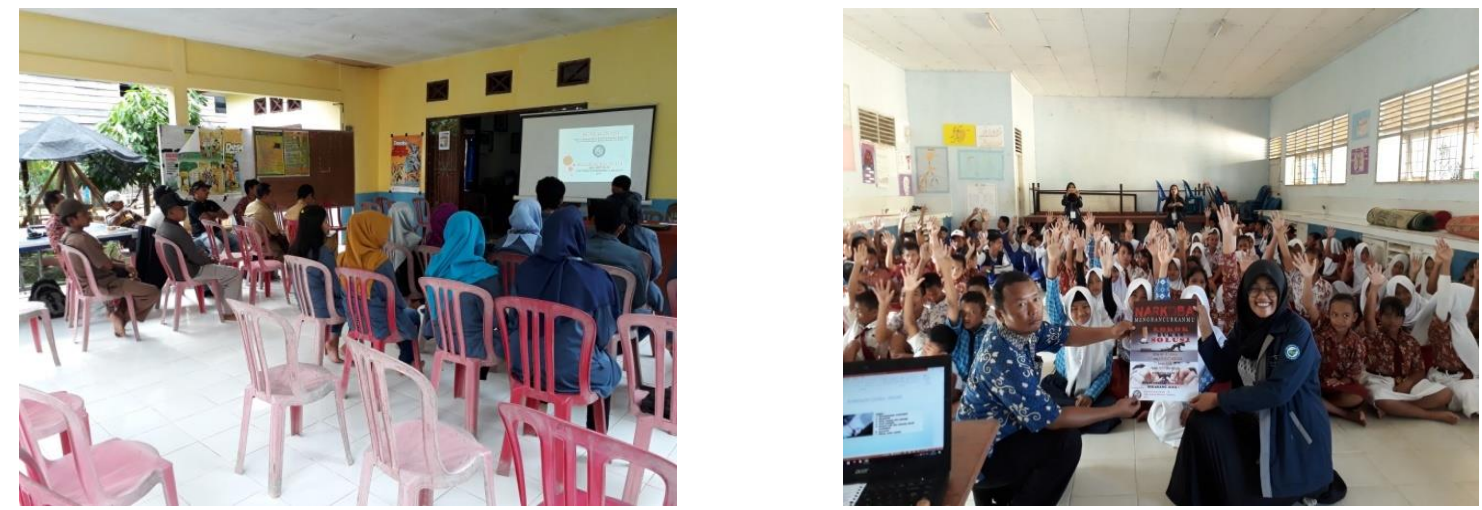

Gambar 3. Kegiatan Memberi Westafel Kepada Sekolah SDN 005 Sebatik Barat dan Sosialisasi bahaya Narkoba di SMP Negeri 1 Sebatik Barat

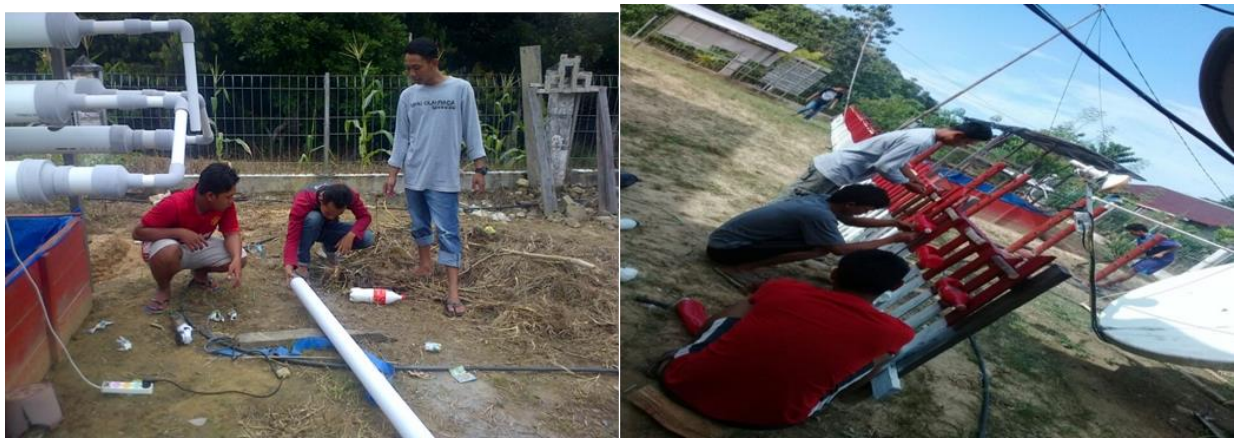

Gambar 4. Pembuatan Kolam Pipa Hidroponik dan Vertikultur

Berdasarkan data kepuasan dan pemahaman gerakan revolusi mental Indonesia bersih maka kemudian dilakukan wawancara kepada masyarakat dan perangkat desa yang puas dan belum memahami gerakan revolusi mental
Indonesia bersih, namun pernah menerapkan. Wawancara berisi tentang metode yang dominan dilakukan oleh masyarakat dan perangkat desa yang terlibat. Berdasarkan hasil data masih banyak masyarakat dan perangkat desa yang puas 
dan memahami gerakan revolusi mental Indonesia bersih sebanyak 78\%. Minimnya sosialisasi gerakan revolusi mental secara massif merupakan salah satu alasan diperlukan adanya kegiatan sosialisasi gerakan revolusi mental secara massif dan berkesinambungan agar masyarakat memahami dan berdampak akan perubahan tingkah laku di masyarakat kecamatan Sebatik Barat.

Kegiatan Pengabdian berbasis revolusi Mental merupakan integrasi mahasiswa dengan dosen memfokus spesifik berbasis pada nilai-nilai strategi Revolusi Mental, yaitu integritas, etos kerja, dan gotong royong, dengan implementasi melalui sikap/ perilaku hidup bersih. Dalam proses mempraktekkkan ilmu dan menerapkan hasil penelitian yang dilaksanakan oleh civitas akedemika, maka perlu suatu media yang mendukung, pengabdian berbasis Revolusi mental merupakan sebuah media yang efektif dan edukatif, meraka akan dapat menangkap dan menghayati denyut nadi kehudupan masyarakat. Melalui gerakan Indonesia Bersih KKN-Revolusi Mental Universitas Borneo Tarakan Menuju kesadaran dan kepedulian baik masyarakat maupun pemerintahan desa terhadap kebersihan lingkungan.

\section{B. Aksi Revolusi Mental Gerakan Indonesia Bersatu}

Gerakan Indonesia Bersatu (GIBe) adalah gerakan para Penyelenggara Negara dan masyarakat untuk mewujudkan perilaku saling menghargai dan gotong-royong untuk memperkuat jati diri dan karakter bangsa berdasarkan 4 (empat) konsensus bangsa yaitu Pancasila, UUD 1945, Bhinneka Tunggal Ika, dan NKRI. Keberagaman yang dimiliki oleh bangsa Indonesia adalah suatu berkah yang dilimpahkan oleh Tuhan Yang Maha Esa, yang dititipkan kepada seluruh rakyat Indonesia. Gerakan Indoensia Bersatu merupakan salah satu upaya untuk menjaga keberagaman yang merupakan modal, kekayaan sosial budaya bangsa dan kekuatan nasional yang luar biasa dalam memposisikan Indonesia dalam dunia internasional. Gerakan ini dilakukan oleh para penyelenggara negara dan masyarakat yang saling bersinergi untuk mewujudkan perilaku saling menghargai dan gotong royong dalam setiap sektor kehidupan.

Dalam Proses kegiatan Pengabdian masyarakat berbasis revolusi mental di Kecamatan Sebatik Barat Kabupaten Nunukan terfokus pada gerakan bersatu di wilayah perbatasan. Banyaknya permasalahan di wilayah perbatasan menjadi bahan pengabdian masyarakat berbasis revolusi mental, diantaranya Memperbaiki Tugu Perbatasan dan Batas desa, Mempererat kembali kebersatuan di wilayah perbatasan melalui perlombaan, memberikan spanduk/baliho ajakan Gerakan Indonesia Bersatu, dan Mengaktifkan kembali Karang Taruna sebagai wadah gerakan pemuda desa untuk menjaga wilayah perbatasan dan Membantu dalam penyelesaian permasalahan di masyarakat yang mengancam persatuan dan kesatuan bangsa (terorisme, radikalisme, SARA, dll). Berikut ini kegiatan-kegiatan Pengabdian berbasis Revolusi Mental yaitu gerakan Indonesia Bersatu di Kecamatan Sebatik Barat dengan Desa Setabu, Desa Liang Bunyu dan Desa Bambangan.

Dalam Proses Pengabdian masyarakat berbasis revolusi mental merupakan gerakan nasional untuk mengubah pandang, pola pikir, sikap-sikap nilai-nilai, dan perilaku masyarakat kecamatan sebatik barat untuk meujudkan masyarakat berdaulat dan berkepribadian yang bertumbu pada tiga nilai-nilai dasar yaitu Integritas, Etos Kerja, dan Gotong Royong. Dalam kegiatan gerakan Indonesia Bersatu menekankan nilai gotong royong yang dapat diartikan sebagai sebuah kenyakinan mengenai pentingnya melakukan kegiatan Bersama-sama menjalin silahturahmi, dan penyelesaian permasalahan di masyarakat yang mengancam persatuan dan kesatuan bangsa (terorisme, radikalisme, SARA, dll). Gotong royong dalam gerakan Indonesia bersatu melibatkan kesadaran setiap lapiran masyarakat dimulai diri sendiri, hingga pada 

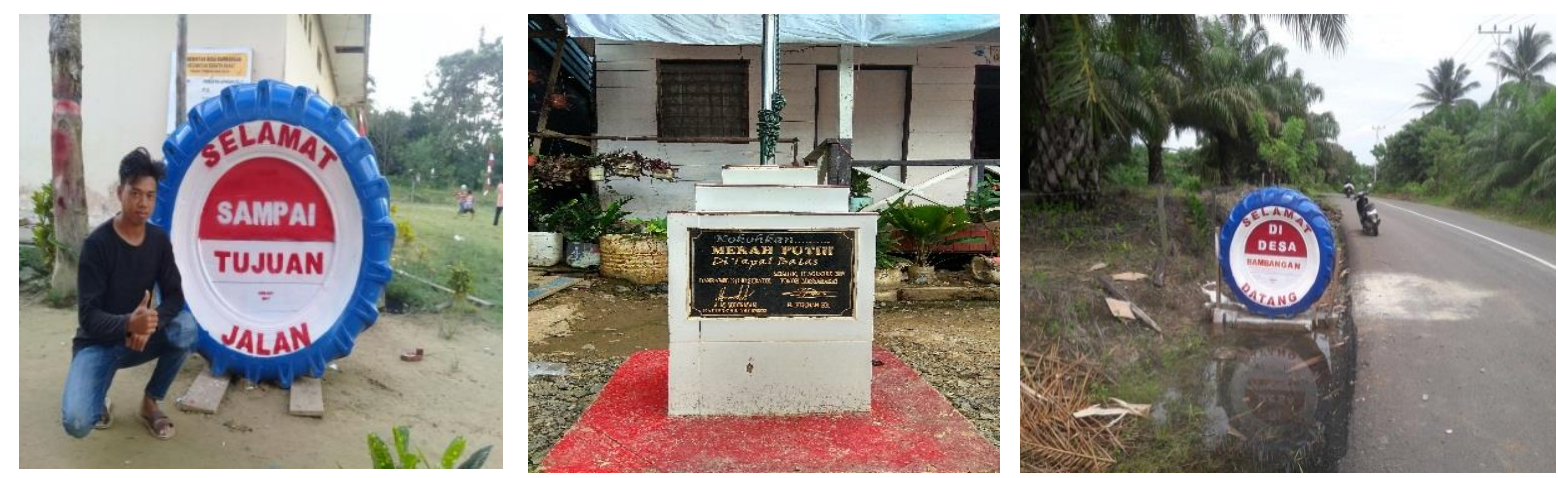

Gambar 5. Memperbaiki Tapal Batas Dan Batas Desa

\section{KESIMPULAN}

\section{Kegiatan Program Kemitraan Masyarakat berbasis Revolusi mental dengan gerakan Indonesia Bersih dan Gerakan Indonesia Bersatu Kecamatan Sebatik Barat di Desa Setabu, Desa Liang Bunyu dan Desa Bambangan berjalan dengan baik. Program Kemitraan Masyarakat berbasis Revolusi mental melatih masyarakat dan memberikan pembekalan ilmu pengetahuan untuk mengembangkan potensi yang dimiliki, baik potensi alam maupun potensi yang ada di dalam diri masyarakat.}

Melalui gerakan Indonesia Bersih Program Kemitraan Masyarakat Revolusi Mental Universitas Borneo Tarakan Menuju kesadaran dan kepedulian baik masyarakat maupun pemerintahan desa terhadap kebersihan lingkungan dan meningkatkan tingkat kesadaran nasionalismes, meningkatkan kehidupan harmonis di masyarakat desa.

\section{REFERENSI}

Katalog Badan Pusat Statistik. 2016. Kecamatan Sebatik Barat Dalam Angka 2016. BPS. Kabupaten Nunukan

Katalog Badan Pusat Statistik. 2017. Statistik Daerah Kecamatan Sebatik Barat 2017. BPS. Kabupaten Nunukan

Katalog Badan Pusat Statistik. 2016. Kalimantan Utara Dalam Angka 2016. BPS Provinsi Kalimantan Timur 